\title{
Sistem Pakar Diagnosa Hama Dan Penyakit Pada Tanaman Apel Menggunakan Metode Certainty Factor
}

\author{
Alfan Hadi Permana ${ }^{1}$, Rosa Andrie Asmara ${ }^{2}$, Ariadi Retno Tri H.R ${ }^{3}$ \\ ${ }^{1}$ Program Studi Teknik Informatika, ${ }^{2,3}$ Jurusan Teknik Elektro, Politeknik Negeri Malang \\ ${ }^{1}$ permana.alfan@gmail.com
}

\begin{abstract}
ABSTRAK
Apel merupakan tanaman buah tahunan yang berasal dari daerah Asia Barat dengan iklim sub tropis. Di Indonesia apel mulai ditanam pada tahun 1934, hingga saat ini tanaman apel sudah banyak ditanam di berbagai wilayah. Apel dapat tumbuh dan berbuah dengan baik di daerah dataran tinggi. Di Kota Batu, Jawa Timur, apel merupakan buah yang menjadi ikon kota wisata ini. Apel di Kota Batu sudah mulai ditanam sejak tahun 1950 dan berkembang pesat pada tahun 1960-an hingga saat ini. Seiring berkembangnya tanaman apel di kota batu, pengendalian hama dan penyakit pada tanaman apel juga perlu dilakukan dengan baik. Pakar atau pihak yang berkompeten dalam bidangnyalah yang dapat memberikan solusi dalam setiap permasalah yang dihadapi oleh petani. Keterbatasan jumlah pakar dan pengetahuan menjadi kesulitan dalam proses identifikasi hama dan penyakit tanaman apel. Penelitian ini bertujuan untuk merancang dan mengimplementasikan suatu sistem yang disebut sistem pakar.

Sistem pakar adalah program atau aplikasi perangkat lunak yang digunakan untuk memecahkan masalah yang biasanya diselesaikan oleh seorang pakar. Aplikasi sistem pakar berbasis website banyak dimanfaatkan oleh berbagai kalangan masyarakat, dapat mengambil keputusan dengan cepat merupakan nilai lebih dalam aplikasi sistem pakar. Metode yang digunakan pada penelitian ini adalah certainty factor $(C F)$, metode tersebut menyatakan tingkat kepercayaan dalam sebuah kejadian atau fakta berdasarkan bukti ataupun penilaian dari seorang pakar.
\end{abstract}

Kata kunci : sistem pakar, tanaman apel, hama dan penyakit, metode certainty factor

\section{PENDAHULUAN}

Kecerdasan buatan atau Artificial Intellegence (AI) dapat didefinisikan sebagai mesin cerdas yang dapat membantu melakukan hal-hal yang sebelumnya dapat dilakukan oleh manusia. Menurut Encyclopedia Britania kecerdasan buatan merupakan cabang dari ilmu komputer yang dalam merepresentasi pengetahuan lebih banyak menggunakan bentuk simbol-simbol daripada bilangan, dan memproses informasi berdasarkan metode heuristic atau dengan berdasarkan sejumlah aturan.

Salah satu cabang dari kecerdasan buatan adalah Expert System atau sistem pakar, yaitu program penasehat berbasis komputer yang mencoba meniru proses berpikir dan pengetahuan dari seorang pakar dalam menyelesaikan masalah-masalah spesifik. Sistem pakar merupakan perangkat lunak yang digunakan untuk memecahkan masalah yang biasanya diselesaikan oleh seorang pakar. Aturanaturan di dalamnya memberitahu program, bagaimana ia memberlakukan informasi-informasi yang tersimpan. Berdasarkan itu program memberikan solusi-solusi atau bantuan mengambil keputusan mengenai permasalahan tertentu, mirip dengan saran seorang pakar.

Apel merupakan tanaman buah tahunan yang berasal dari daerah Asia Barat dengan iklim sub tropis. Di Indonesia apel telah ditanam sejak tahun 1934 hingga saat ini. Apel dapat tumbuh dan berbuah baik di daerah dataran tinggi. Salah satu sentra produksi apel di Indonesia adalah Batu dan Poncokusumo, Kab. Malang.
Di Kota Batu, kegiatan budidaya apel berlangsung hampir setiap tahunnya dengan dua kali masa panen. Pengendalian hama dan penyakit merupakan salah satu faktor terpenting dalam perkembangan tanaman apel. Para petani biasanya melakukan pencegahan dengan melakukan penyemprotan setiap 1 - 2 minggu sekali dengan dosis ringan. Pencegahan ini agar hama dapat segera ditanggulangi dan baik dilakukan di pagi atau sore hari. Terkadang petani juga membutuhkan seorang pakar dalam menentukan jenis hama dan penyakit pada tanaman apel agar dapat memberikan solusi terbaik. Demikian pula jika ditemukan adanya jenis hama dan penyakit baru pada tanaman apel, maka seorang pakar harus melakukan penelitian guna mendapatkan keterangan dari hama dan penyakit baru tersebut dan secepat mungkin memberikan sosialisasi kepada para petani mengenai jenis hama dan penyakit baru tersebut beserta cara penanganannya. Akan tetapi, keterbatasan yang dimiliki seorang pakar terkadang menjadi kendala bagi para petani yang akan melakukan konsultasi guna menyelesaikan suatu permasalahan untuk mendapatkan solusi terbaik. Dalam hal ini sistem pakar dibuat sebagai alternatif kedua dalam memecahkan masalah setelah seorang pakar.

Aplikasi sistem pakar diharapkan dapat menjadi sarana untuk konsultasi, sarana pembelajaran disebuah instansi Dinas Pertanian dan Kehutanan Kota Batu serta dapat dijadikan sebagai alat bantu bagi seorang pakar dalam mendiagnosa dan mensosialisasikan jenis hama dan penyakit tanaman apel kepada para petani ataupun masyarakat awam. 


\section{METODE PENELITIAN}

Metode penelitian merupakan cara atau teknik ilmiah memperoleh data dengan tujuan dan kegunaan tertentu. Cara atau teknik ilmiah yang dimaksud adalah dimana kegiatan penelitian itu dilaksanakan berdasarkan ciri-ciri keilmuan, yaitu rasional, empiris dan sistematis (RES). Metode yang digunakan dalam penelitian ini mengacu pada proses pembangunan aplikasi sistem pakar pada umumnya dengan menggunakan konsep System Development Life Cycle (SDLC). Proses identifikasi masalah, pengumpulan data, analisa perancangan, dan pengujian aplikasi merupakan bagian terpenting dalam konsep SDLC. Penekanan dilakukan pada proses identifikasi masalah dan analisis perancangan serta pengujian aplikasi.

Pemenuhan konsep sistem pakar dengan berbasis pengetahuan dilakukan dengan pengumpulan data dan informasi yang terkait dengan hama dan penyakit pada tanaman apel. Dengan melakukan studi pustaka dan konsultasi secara langsung terhadap pakar yang berpengalaman. Basis data dilakukan dengan analisis dan perancangan menggunakan model diagram konteks, dan Entity Relationship Diagram (ERD). Adapun konsep yang digunakan dalam penelitian ini dengan menggunakan forward chaining serta penilaian bobot menggunakan model Certainty Factor (CF). Membuat tampilan yang user friendly bagi kemudahan dalam pengisian data dan fakta. Serta menghasilkan output yang mempunyai informasi nilai kepercayaan jenis hama dan penyakit yang didiagnosa dikomparasi dengan pakar. Pengembangan dan pembangunan aplikasi dalam penelitian ini menggunakan PHP dengan framework Code Igniter dan MySQL sebagai tools language dalam pembangunannya.

\section{A. Hama dan Penyakit Tanaman Apel}

Tabel 1 Hama Tanaman Apel

\begin{tabular}{|c|c|c|}
\hline $\begin{array}{l}\text { Nama } \\
\text { Hama }\end{array}$ & Nama Latin & Gejala \\
\hline Kutu Hijau & $\begin{array}{l}\text { Aphispomi } \\
\text { Geer }\end{array}$ & $\begin{array}{l}\text { - Hama } \\
\text { menghisap cairan } \\
\text { sel daun } \\
\text { - Terdapat hama } \\
\text { pada permukaan } \\
\text { daun muda, } \\
\text { tangkai, bunga dan } \\
\text { buah } \\
\text { - Terdapat embun } \\
\text { madu pada } \\
\text { permukaan daun } \\
\cdot \text { Tumbuhnya } \\
\text { jamur hitam pada } \\
\text { daun } \\
\text { - Daun berubah } \\
\text { bentuk } \\
\text { - Terlambat }\end{array}$ \\
\hline
\end{tabular}

\begin{tabular}{|c|c|c|}
\hline & & $\begin{array}{l}\text { berbunga } \\
\cdot \text { Buah mudah } \\
\text { gugur } \\
\cdot \text { Mutu buah jelek }\end{array}$ \\
\hline Tungau & $\begin{array}{l}\text { Panonychus } \\
\text { Ulmi }\end{array}$ & $\begin{array}{l}\text { - Hama } \\
\text { menghisap cairan } \\
\text { sel daun } \\
\text { - Bercak kuning } \\
\text { pada daun } \\
\cdot \text { Daun berubah } \\
\text { mengering } \\
\text { - Bercak keperak- } \\
\text { perakan pada buah }\end{array}$ \\
\hline Trips & & $\begin{array}{l}\cdot \text { Hama } \\
\text { menyerang tunas } \\
\text { dan buah } \\
\text { - Daun terlihat } \\
\text { bintik putih } \\
\cdot \text { Daun } \\
\text { menggulung ke } \\
\text { atas } \\
\text { - Pertumbuhan } \\
\text { daun tidak normal } \\
\text { - Daun berubah } \\
\text { mengering } \\
\text { - Daun terdapat } \\
\text { bekas luka } \\
\text { berwarna coklat }\end{array}$ \\
\hline Ulat Daun & $\begin{array}{l}\text { Spodoptera } \\
\text { litura }\end{array}$ & $\begin{array}{l}\cdot \text { Hama } \\
\text { menyerang daun } \\
\cdot \text { Lubang tidak } \\
\text { teratur pada daun }\end{array}$ \\
\hline $\begin{array}{l}\text { Serangga } \\
\text { Penghisap } \\
\text { Daun }\end{array}$ & Helopelthis Sp & $\begin{array}{l}\cdot \text { Hama } \\
\text { menghisap cairan } \\
\text { sel daun } \\
\text { - Daun terdapat } \\
\text { bekas luka } \\
\text { berwarna coklat } \\
\cdot \text { Tunas yang } \\
\text { terserang menjadi } \\
\text { coklat dan kering } \\
\cdot \text { Bercak keperak- } \\
\text { perakan pada buah } \\
\cdot \text { Mutu buah jelek }\end{array}$ \\
\hline $\begin{array}{l}\text { Ulat Daun } \\
\text { Hitam }\end{array}$ & $\begin{array}{l}\text { Dasychira } \\
\text { Inclusa Walker }\end{array}$ & $\begin{array}{l}\cdot \text { Hama } \\
\text { menyerang daun } \\
\cdot \text { Kerusakan pada } \\
\text { daun hingga } 30 \% \\
\cdot \text { Terdapat larva } \\
\text { dibalik daun } \\
\end{array}$ \\
\hline Lalat Buah & $\begin{array}{l}\text { Rhagoletis } \\
\text { Pomonella }\end{array}$ & $\begin{array}{l}\text { - Mutu buah jelek } \\
\text { - Benjol-benjol } \\
\text { pada buah }\end{array}$ \\
\hline
\end{tabular}

Tabel 2 Penyakit Tanaman Apel 


\begin{tabular}{|c|c|c|}
\hline $\begin{array}{l}\text { Nama } \\
\text { Penyakit }\end{array}$ & Nama Latin & Gejala \\
\hline $\begin{array}{l}\text { Penyakit } \\
\text { Embun } \\
\text { Tepung }\end{array}$ & $\begin{array}{l}\text { Powdery } \\
\text { Mildew }\end{array}$ & $\begin{array}{l}\text { - Permukaan } \\
\text { daun tampak } \\
\text { putih } \\
\text { - Tunas tidak } \\
\text { normal dan } \\
\text { tidak berbuah } \\
\text { - Buah } \\
\text { berwana coklat, } \\
\text { kulit berwarna } \\
\text { coklat }\end{array}$ \\
\hline $\begin{array}{l}\text { Penyakit } \\
\text { Bercak } \\
\text { Daun }\end{array}$ & $\begin{array}{l}\text { Marssonina } \\
\text { Coronaria J.J. } \\
\text { Davis }\end{array}$ & $\begin{array}{l}\text { - Pada saat } \\
\text { perompesan } \\
\text { terlihat bercak } \\
\text { putih } \\
\text { - Timbul titik } \\
\text { hitam pada } \\
\text { daun } \\
\text { - Daun } \\
\text { berguguran } \\
\end{array}$ \\
\hline $\begin{array}{l}\text { Penyakit } \\
\text { Kanker }\end{array}$ & $\begin{array}{l}\text { Botryosphaeria } \\
\text { Sp. }\end{array}$ & $\begin{array}{l}\text { - Batang atau } \\
\text { cabang } \\
\text { membusuk } \\
\text { - Batang atau } \\
\text { cabang } \\
\text { mengeluarkan } \\
\text { cairan } \\
\text { - Buah } \\
\text { berwarna } \\
\text { coklat, berkulit } \\
\text { coklat } \\
\text { - Buah } \\
\text { membusuk }\end{array}$ \\
\hline $\begin{array}{l}\text { Busuk } \\
\text { Buah }\end{array}$ & $\begin{array}{l}\text { Gloeosporium } \\
\text { Sp. }\end{array}$ & $\begin{array}{l}\text { - Buah bercak } \\
\text { kecil coklat } \\
\text { - Timbul bintik } \\
\text { hitam pada } \\
\text { buah }\end{array}$ \\
\hline $\begin{array}{l}\text { Busuk } \\
\text { Akar }\end{array}$ & $\begin{array}{l}\text { Armilliaria } \\
\text { Melea }\end{array}$ & $\begin{array}{l}\text { - Berada di } \\
\text { daerah dingin } \\
\text { basah } \\
\text { - Daun layu } \\
\text {. Daun } \\
\text { berguguran } \\
\text { - Kulit akar } \\
\text { membusuk }\end{array}$ \\
\hline
\end{tabular}

\section{B. Metode Faktor Kepastian (Certainty Factor)}

Certainty Factor (CF) merupakan salah satu teknik yang digunakan untuk mengatasi ketidakpastian dalam pengambilan keputusan. Certainty Factor $(\mathrm{CF})$ dapat terjadi dengan berbagai kondisi. Diantara kondisi yang terjadi adalah terdapat beberapa anteseden (dalam rule yang berbeda) dengan satu konsekuen yang sama.

Faktor kepastian menyatakan kepercayaan dalam sebuah kejadian (fakta atau hipotesis) berdasarkan bukti atau penilaian pakar. Certainty
Factor menggunakan suatu nilai untuk mengasumsikan derajad keyakinan seorang pakar terhadap suatu data. Giarattano dan Riley,1994 (dalam Kusrini, 2006:25) menyebutkan konsep keyakinan dan ketidakyakinan yang kemudian diformulakan dalam rumusan dasar certainty factor sebagai berikut:

$$
\begin{aligned}
& \mathrm{CF}(\text { Rule })=\operatorname{MB}(\mathrm{H}, \mathrm{E})-\mathrm{MD}(\mathrm{H}, \mathrm{E}) \\
& \mathrm{MB}(\mathrm{H}, \mathrm{E})=\left\{\begin{array}{c}
\frac{\max [\mathrm{P}(\mathrm{H} \mid \mathrm{E}), \mathrm{P}(\mathrm{H})]-\mathrm{P}(\mathrm{H})}{\max [1,0]-\mathrm{P}(\mathrm{H})} \\
\mathrm{MD}(\mathrm{H}, \mathrm{E})=\left\{\frac{\min [\mathrm{P}(\mathrm{H} \mid \mathrm{E}), \mathrm{P}(\mathrm{H})]-\mathrm{P}(\mathrm{H})}{\min [1,0]-\mathrm{P}(\mathrm{H})}\right.
\end{array}\right.
\end{aligned}
$$

Di mana:

$\begin{array}{ll}\mathrm{CF}(\text { Rule }) & =\text { faktor kepastian } \\ \mathrm{MB}(\mathrm{H}, \mathrm{E}) & =\text { measure of belief (ukuran }\end{array}$ $\mathrm{MB}(\mathrm{H}, \mathrm{E}) \quad$ measure of belief (ukuran jika diberikan evidence E (antara 0 dan 1)

$\mathrm{MD}(\mathrm{H}, \mathrm{E}) \quad=$ measure of disbelief (ukuran ketidakpercayaan) terhadap hipotesis $\mathrm{H}$, jika diberikan evidence E (antara 0 dan 1)

$\mathrm{P}(\mathrm{H}) \quad$ probabilitas kebenaran hipotesis $\mathrm{H}$

$\mathrm{P}(\mathrm{H} \mid \mathrm{E}) \quad=$ probabilitas bahwa $\mathrm{H}$ benar karena fakta $\mathrm{E}$

\section{III.HASIL}

Pada aplikasi sistem pakar terdapat 3 bagian utama, yaitu knowledge base (tempat penyimpanan informasi yang aktual), inference engine (proses penalaran) untuk pencarian solusi dan kesimpulan yang datanya dikirim oleh user dan faktanya tersimpan pada knowledge base, dan user interface (layar sajian menu untuk sistem pakar berkomunikasi dengan user) (Duval et al., 1994).

Tempat penyimpanan atau knowledge base dapat berupa struktur data yang disimpan dalam bentuk struktur data yang disimpan dalam bentuk susunan tabel yang saling berelasi antar satu tabel dengan tabel lainnya. Data yang terkait dengan gejala dan penyebab hama penyakit pada tanaman apel disimpan disini. Susunan ERD yang dirancang dapat dilihat pada gambar 1 . 


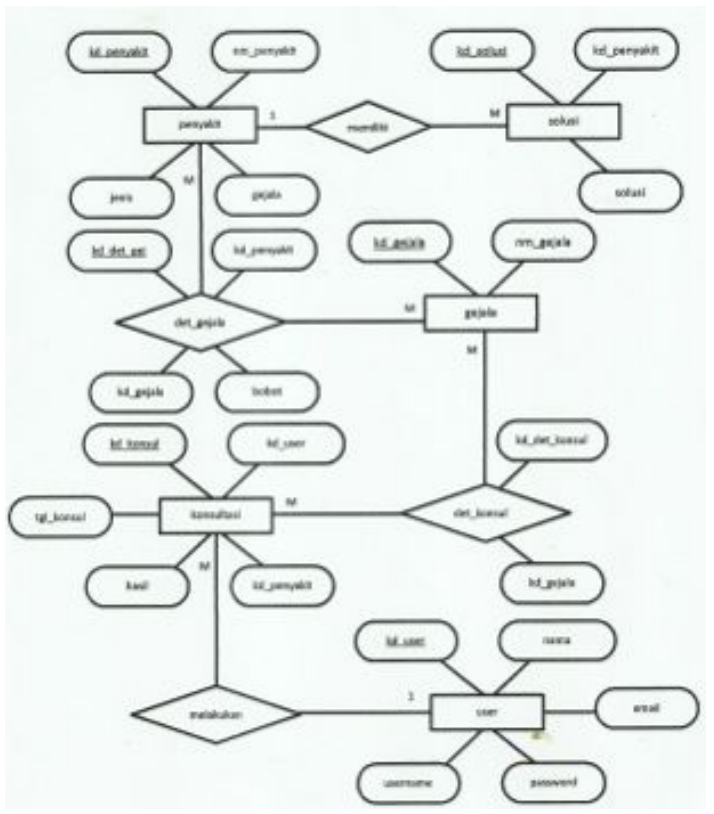

Gambar 1 Entity Relation Diagram pada knowledge base.

Pada bagian inference engine, digunakan bentuk production rules. Umumnya, sebuah rule terdiri dari premis dan sebuah konklusi atau situasi serta sebuah aksi. Pernyataan yang digunakan dalam penulisan adalah $I F-T H E N$. Hubungan "ifthen-else" adalah tiruan dari cara seorang pakar dalam penyelesaian masalah yang sulit. Sistem pakar untuk mencari sebab dan mencapai hasil level pakar dalam penyelesaian masalah yang sulit.

Berikut rule yang diterapkan pada penelitian ini: R1 = IF Hama menghisap cairan sel daun AND Terdapat hama pada permukaan daun muda, tangkai, bunga dan buah AND Terdapat embun madu pada permukaan daun AND Tumbuhnya jamur hitam pada daun AND Daun berubah bentuk AND Terlambat berbunga AND Buah mudah gugur AND Mutu buah jelek THEN Hama = Kutu Hijau

R2 = IF Hama menghisap cairan sel daun AND Bercak kuning pada daun AND Daun berubah mengering AND Bercak keperak-perakan pada buah THEN Hama= Tungau

R3 = IF Hama menyerang tunas dan buah AND Daun terlihat bintik putih AND Daun menggulung ke atas AND Pertumbuhan daun tidak normal AND Daun berubah mengering AND Daun terdapat bekas luka berwarna coklat THEN Hama $=$ Trips

R4 = IF Hama menyerang daun AND Lubang tidak teratur pada daun THEN Hama = Ulat Daun

R5 = IF Hama menghisap cairan sel daunAND Daun terdapat bekas luka berwarna coklat AND Tunas yang terserang menjadi coklat dan kering AND Bercak keperak-perakan pada buah AND
Mutu buah jelek THEN Hama = Serangga Penghisap Daun

R6 = IF Hama menyerang daun AND Kerusakan pada daun hingga 30\% AND Terdapat larva dibalik daun THEN Hama = Ulat Daun Hitam

R7 = IF Mutu buah jelek AND Benjol-benjol pada buah THEN Hama = Lalat Buah

R8 = IF Permukaan daun tampak putih AND Tunas tidak normal dan tidak berbuah AND Buah berwana coklat, kulit berwarna coklat THEN Penyakit $=$ Penyakit Embun Tepung

R9 = IF Pada saat perompesan terlihat bercak putih AND Timbul titik hitam pada daun AND Daun berguguran THEN Penyakit $=$ Penyakit Bercak Daun

R10 = IF Batang atau cabang membusuk AND Batang atau cabang mengeluarkan cairan AND Buah berwarna coklat, berkulit coklat AND Buah membusuk THEN Penyakit = Penyakit Kanker

R11 = IF Buah bercak kecil coklat AND Timbul bintik hitam pada buah THEN Penyakit $=$ Busuk Buah

R12 = IF Berada di daerah dingin basah AND Daun layu AND Daun berguguran AND Kulit akar membusuk THEN Penyakit = Busuk Akar

Bagian lain dari sistem ini adalah tampilan user atau user interface diberikan sajian menu yang menampilkan beberapa jenis gejala yang dapat dipilih (Gambar 2). User dapat menentukan gejalagejala yang ditemui para petani apel. Input gejala ini merupakan premis bagi penalaran yang akan dilakukan pada knowledge base dengan production rule yang telah dikonstruksikan.

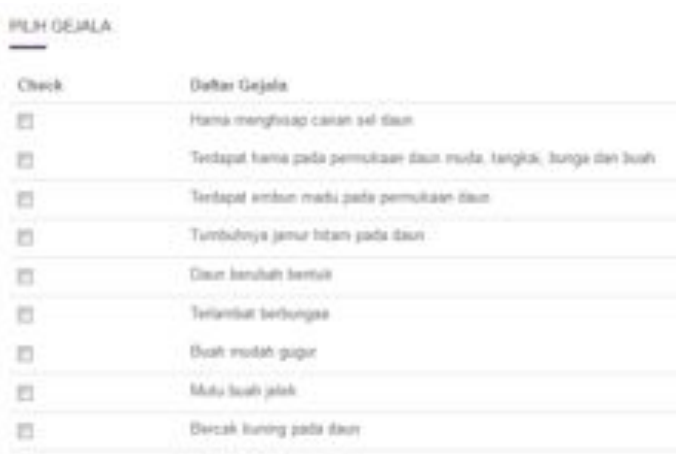

Gambar 2 Pilihan daftar gejala

Perancangan pada halaman admin juga dilakukan untuk memasukkan data-data yang dibutuhkan, seperti data hama penyakit, gejala, solusi, user, dan berita yang akan ditampilkan pada halaman untuk user atau pengunjung. Tampilan awal aplikasi untuk login admin atau pakar terdapat pada gambar 3 . 


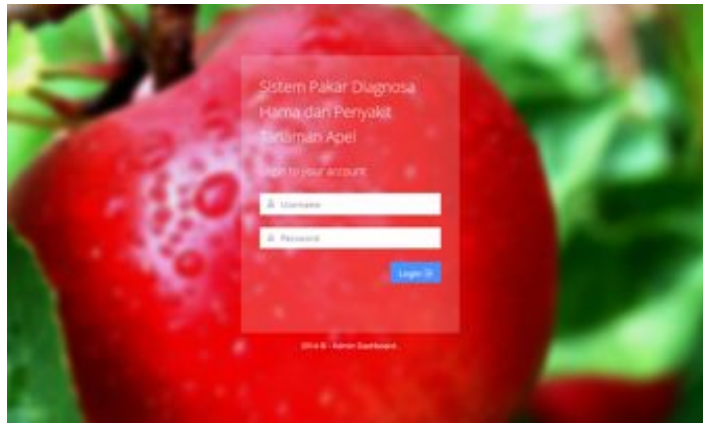

Gambar 3 Halaman login admin dan pakar

Halaman untuk inputan data hama penyakit, gejala, detail gejala, dan solusi.
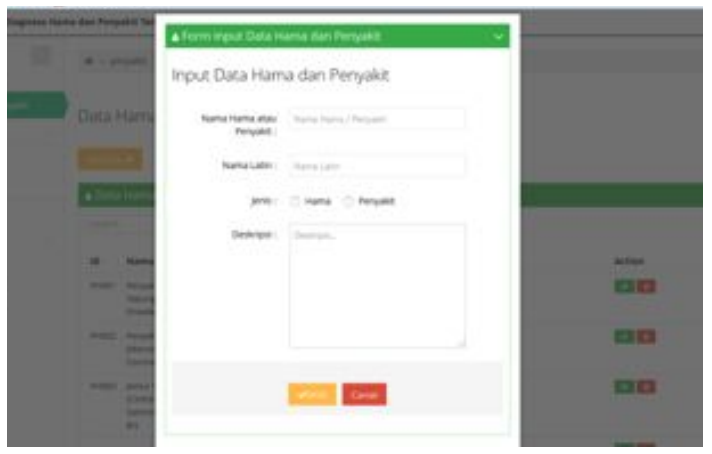

Gambar 4 Halaman Input Data Hama Penyakit

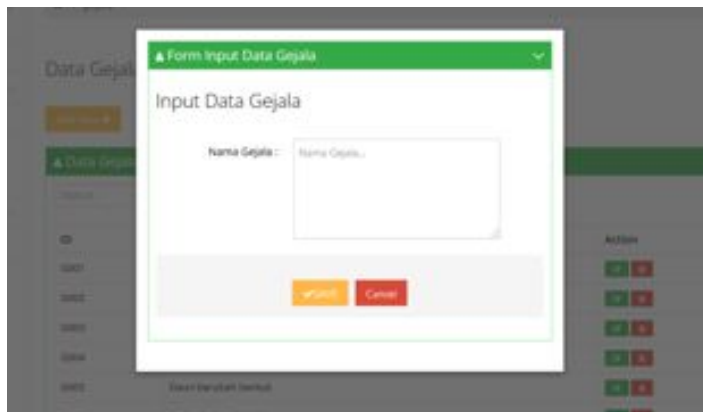

Gambar 5 Halaman Input Data Gejala

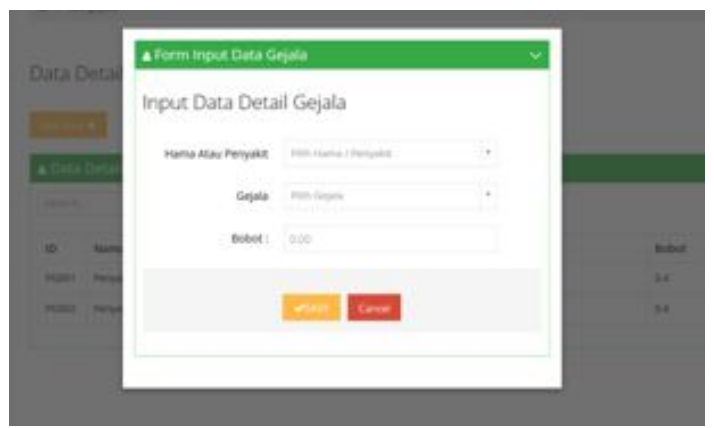

Gambar 6 Halaman Input Data Detail Gejala Penyakit

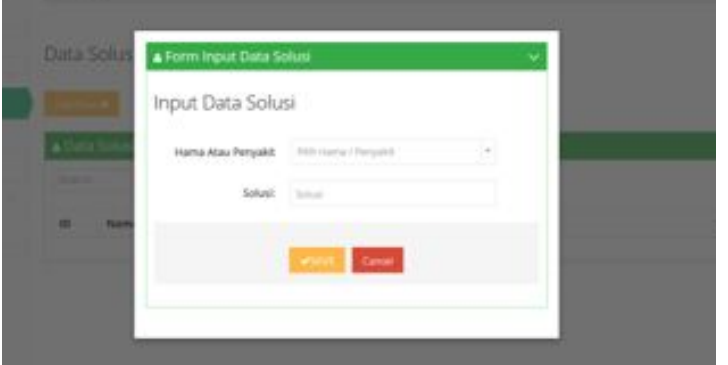

Gambar 7 Halaman Input Data Solusi

\section{IV.PEMBAHASAN}

Berisi tentang penerapan metode didalam sistem aplikasi. Dilakukan dengan tahap implementasi dan pengujian sistem. Penggunaan metode certainty factor pada aplikasi ini dengan menggunakan aturan perhitungan nilai CFpakar dengan CFuser menggunakan persamaan :

$$
\begin{aligned}
\mathrm{CF}(\mathrm{H}, \mathrm{E}) & =\mathrm{CF}(\mathrm{E}) * \mathrm{CF}(\text { rule }) \\
& =\mathrm{CF}(\text { user }) * \mathrm{CF}(\text { pakar })
\end{aligned}
$$

Pada sesi konsultasi sistem, pengguna (user) diberi pilihan jawaban yang masing - masing memiliki bobot sebagai berikut:

Pilihan jawaban dengan tingkat keyakinan:

- $\quad$ Tidak $=0$

- $\quad$ Sedikit yakin $=0,4$

- $\quad$ Cukup yakin $=0,6$

- $\quad$ Yakin $=0,8$

- $\quad$ Sangat yakin $=1$

Sebagai contoh, proses pemberian bobot pada setiap premis (gejala) hingga perolehan prosentase keyakinan untuk Penyakit Embun Tepung pada musim hujan.

Rule1:

IF Permukaan daun tampak putih

AND Tunas tidak normal dan tidak berbuah

AND Buah berwana coklat, kulit berwarna coklat

THEN Penyakit = Penyakit Embun Tepung

Langkah pertama adalah pemecahan rule dengan premis majemuk menjadi rule dengan premis tunggal, seperti dibawah ini :

IFPermukaan daun tampak putih THENPenyakit Embun Tepung

IFTunas tidak normal dan tidak berbuah THENPenyakit Embun Tepung

IFBuah berwana coklat, kulit berwarna coklat THENPenyakit Embun Tepung

Kemudian pakar menentukan nilai CF pakar untuk masing-masing premis sebagai berikut:

$\mathrm{CF}_{\text {pakar }}$ (Permukaan daun tampak putih $)=0,6$

$\mathrm{CF}_{\text {pakar }}$ (Tunas tidak normal dan tidak berbuah) $=0,4$

$\mathrm{CF}_{\text {pakar }}$ (Buah berwana coklat, kulit berwarna coklat) $=0,4$ 
Kemudian dilanjutkan dengan penentuan $\mathrm{CF}$ user, misalkan user memilih jawaban sebagai berikut :

- $\mathrm{CF}_{\text {user }}$ (Permukaan daun tampak putih) $=0,8$

- $\mathrm{CF}_{\text {user }}$ (Tunas tidak normal dan tidak berbuah) = 0,6

- $\mathrm{CF}_{\text {user }}$ (Buah berwana coklat, kulit berwarna coklat) $=0,4$

Selanjutnya dihitung CFpakar dengan CFuser menggunakan persamaan :

$$
\begin{aligned}
\mathrm{CF}(\mathrm{H}, \mathrm{E}) & =\mathrm{CF}(\mathrm{E}) * \mathrm{CF}(\text { rule }) \\
& =\mathrm{CF}(\text { user }) * \mathrm{CF}(\text { pakar }) \\
\mathrm{CF} 1.1 & =0.6^{*} 0.8=0.48 \\
\mathrm{CF} 1.2 & =0.4^{*} 0.6=0.24 \\
\mathrm{CF} 1.3 & =0.4^{*} 0.4=0.16
\end{aligned}
$$

Langkah terakhir adalah mengkombinasikan nilai $\mathrm{CF}$ dari masing-masing rule :

$\mathrm{CF}_{\text {COMBINE }}(\mathrm{CF} 1, \mathrm{CF} 2)=\mathrm{CF} 1+\mathrm{CF} 2 *(1-\mathrm{CF} 1)$;

jika semuanya $>0$

Kombinasi CF $\quad 1.1$ dengan $\mathrm{CF} \quad 1.2$ dengan persamaan diatas, karena nilai CF 1.1 dan CF 1.2 lebih besar dari 0 .

$\mathrm{CF}_{\text {COMBINE }}\left(\mathrm{CF}_{1}, \mathrm{CF}_{2}\right)=\mathrm{CF}_{1}+\mathrm{CF}_{2} *(1-$ $\mathrm{CF}_{1}$ ), sehingga menjadi.

(1-0.48)

$$
\mathrm{CF}_{\mathrm{COMBINE}}\left(\mathrm{CF}_{1.1}, \mathrm{CF}_{1.2}\right)=0.48+0.24 *
$$

$$
\begin{aligned}
& =0.48+0.1248 \\
& =0.6048 \mathrm{CF}_{\text {old }}
\end{aligned}
$$

Kombinasikan CFold dan CF 1.3 $(1-0.6048)$

$$
\mathrm{CF}_{\text {COMBINE }}\left(\mathrm{CF}_{\text {old }}, \mathrm{CF}_{1.3}\right)=0.6048+0.16 \text { * }
$$

$$
\begin{aligned}
& =0.6048+0.063232 \\
& =0.668032 \mathrm{CF}_{\text {old }}
\end{aligned}
$$

Prosentase keyakinan $=\mathrm{CF}_{\mathrm{COMBINE}} * 100 \%$

$$
=66 \%
$$

Dengan demikian dapat dikatakan bahwa perhitungan certainty factor yang dilakukanpada jenis Penyakit Embun Tepung memiliki tingkat keyakinan sistem $66 \%$.

\section{KESIMPULAN DAN SARAN}

Sistem pakar merupakan sistem aplikasi yang dibuat menyerupai seorang pakar atau ahli untuk memudahkan pengguna dalam mendiagnosa penyakit dalam memutuskan suatu diagnosa. Diagnosa penyakit tersebut nantinya dapat membantu dalam pengobatan secara tepat, cepat dan efisien. Hal tersebut diharapkan dapat membantu mengurangi kerugian yang dapat ditimbulkan akibat hama penyakit yang menyerang.

Keunggulan dari penerapan sistem pakar untuk hama penyakit tanaman apel sangatlah bergantung pada tingkat kepercayaan dalam mendukung proses inferensi (penalaran) terhadap data dan fakta yang disimpan pada knowledge base.Sehingga penerapan metode certainty factor pada sistem pakar ini dapat memberikan hasil yang akurat dari perhitungan bobot untuk kesimpulan diagnosis yang dihasilkan. Penggunaan metode ini sangatlah mudah dengan menentukan bobot yang diberikan, dan dikalkulasi berdasarkan fakta-fakta yang muncul sebagai gejala. Hal yang perlu diperhatikan dalam metode $\mathrm{CF}$ ini adalah pemberian nilai bobot terhadap gejala yang ditimbulkan akan berpengaruh terhadap besaran hasil kesimpulan yang diperoleh.

Untuk menyempurnakan sistem pakar diagnosa hama dan penyakit tanaman apel, maka penulis memberikan saran sebagai berikut:

a. Pembaca diharapkan dapat memberikan masukan dalam pengembangan sistem pakar ini dengan menggunakan metode ketidakpastian lainnya.

b. Pembaca dapat menambahkan berbagai inovasi baru ataupun fasilitas yang dibutuhkan untuk mendukung sistem pakar tersebut agar lebih baik dan bermanfaat.

\section{DAFTAR PUSTAKA}

Kusumadewi, S. (2003). Artificial intelligence, Yogyakarta: Graha Ilmu.

Tuswanto dan Fadlil, Abdul : Sistem Pakar Untuk Mendiagnosa Hama Dan Penyakit Tanaman Bawang Merah, Jurnal Sarjana Teknik Informatika Volume 1 No 1, Tahun 2013

Satta Wigenasantana,dkk, (1994), Dasar-dasar Perlindungan Tanaman, Jakarta : Universitas Terbuka

http://www.warintek.ristek.go.id/pertanian/apel.pdf di akses pada tanggal 29 Januari 2014

Sutojo, T dan Mulyanto , Edy ,(2011), Kecerdasan Buatan, Yogyakarta: Andi

Rohajawati, Siti dan Supriyati, Rina : Sistem Pakar Diagnosa Penyakit Unggas dengn Metode Certainty Factor. Tahun 2006

Kusrini. 2006. Sistem Pakar Teori dan Aplikasi. Yogyakarta : Andi

Budi, Komang : Sistem Pakar Indentifikasi Terumbu Karang Menggunakan Metode CertaintyFactor. 